\title{
The Toll-like receptor 2/1 (TLR2/1) complex initiates human platelet activation via the src/Syk/LAT/PLC gamma 2 signalling cascade
}

Knut Fälker, Kristin Klarstrom-Engstrom, Torbjorn Bengtsson, Tomas Lindahl and Magnus

Grenegard

\section{Linköping University Post Print}

\section{Tweet}

N.B.: When citing this work, cite the original article.

Original Publication:

Knut Fälker, Kristin Klarstrom-Engstrom, Torbjorn Bengtsson, Tomas Lindahl and Magnus Grenegard, The Toll-like receptor 2/1 (TLR2/1) complex initiates human platelet activation via the src/Syk/LAT/PLC gamma 2 signalling cascade, 2014, Cellular Signalling, (26), 2, 279-286.

http://dx.doi.org/10.1016/j.cellsig.2013.11.011

Copyright: Elsevier

http://www.elsevier.com/

Postprint available at: Linköping University Electronic Press

http://urn.kb.se/resolve?urn=urn:nbn:se:liu:diva-105241 
The Toll-like receptor 2/1 (TLR2/1) complex initiates human platelet activation via the src/Syk/LAT/PLC $\gamma 2$ signalling cascade

Short title/running head: TLR2/1 complex-initiated activation of human platelets

Knut Fälker ${ }^{\mathrm{a}, \mathrm{b}, *}$, Kristin Klarström-Engström ${ }^{\mathrm{b}}$, Torbjörn Bengtsson ${ }^{\mathrm{b}}$, Tomas L. Lindahl ${ }^{\mathrm{a}}$, Magnus Grenegård ${ }^{\mathrm{b}}$

${ }^{\mathrm{a} D e p a r t m e n t}$ of Clinical and Experimental Medicine, Linköping University, SE-58185 Linköping, Sweden

${ }^{\mathrm{b}}$ Department of Biomedicine, School of Health and Medical Sciences, Örebro University, SE70182 Örebro, Sweden

*Corresponding author: Knut Fälker, Department of Biomedicine, School of Health and Medical Sciences, Örebro University, SE-70182 Örebro, Sweden, e-mail: knut.falker@oru.se, phone: +46-19-301254 


\section{Summary}

The specific TLR2/1 complex activator Pam3CSK4 has been shown to provoke prominent activation and aggregation of human non-nucleated platelets. As Pam3CSK4-evoked platelet activation does not employ the major signalling pathway established in nucleated immune cells, we investigated if the TLR2/1 complex on platelets may initiate signalling pathways known to be induced by physiological agonists such as collagen via GPVI or thrombin via PARs. We found that triggering TLR2/1 complex-signalling with Pam3CSK4, in common with that induced via GPVI, and in contrast to that provoked by PARs, involves tyrosine phosphorylation of the adaptor protein LAT as well as of PLC $\gamma 2$ in a src - and Syk-dependent manner. In this respect, we provide evidence that Pam3CSK4 does not cross-activate GPVI.

Further, by the use of platelets from a Glanzmann's thrombasthenia patient lacking $\beta_{3}$, in contrast to findings in nucleated immune cells, we show that the initiation of platelet activation by Pam3CSK4 does not involve integrin $\beta_{3}$ signalling; whereas the latter, subsequent to intermediate TXA2 synthesis and signalling, was found to be indispensable for proper dense granule secretion and full platelet aggregation. Together, our findings reveal that triggering the TLR2/1 complex with Pam3CSK4 initiates human platelet activation by engaging tyrosine kinases of the src family and Syk, the adaptor protein LAT, as well as the key mediator PLC $\gamma 2$.

Keywords: human platelets, TLR2, Pam3CSK4, Syk, LAT, PLC 2 


\section{Introduction}

The discovery of blood platelets and their pivotal role in thrombosis and hemostasis emerged about 150 years ago [1]. Within the last 15 years it became more and more evident that nonnucleated platelets are also implicated in the adaptive [2] as well as being components of the innate immune system $[3,4]$, the latter which came into focus by the discovery that platelets express Toll-like receptors (TLRs) [5], of which TLR4, TLR2, and TLR9 were found to be the most abundant $[6,7]$.

TLR2, in particular, forms heterodimers with TLR1 or TLR6, which is the prerequisite to recognize a wide spectrum of microbial pathogen-associated molecules such as peptidoglycans and lipopeptides [8, 9]. In nucleated cells of the immune system TLR2/1complex activation triggers a signalling cascade employing the TIR domain-containing adaptor protein (TIRAP)/Mal (MyD88-adaptor-like) and myeloid differentiation factor-88 (MyD88), resulting in an interleukin 1 receptor-associated kinase (IRAK-1)-mediated translocation of the nuclear factor 'kappa-light-chain-enhancer' of activated B-cells (NF- $\mathrm{B}$ ) which finally promotes the expression of inflammatory cytokines [10].

The synthetic triacylated lipopeptide Pam3CSK4 that mimics the acylated amino terminus of bacterial lipopeptides, today recognized as a highly specific agonist of the TLR2/1 complex, has already in 1994 been reported to be an effective activator of human platelets inducing cytosolic calcium $\left(\mathrm{Ca}^{2+}\right)$ mobilization, protein tyrosine phosphorylation, dense granule secretion, and aggregation [11]. Interestingly, the diacylated macrophage activating lipoprotein-2 (MALP-2), which selectively induces TLR2/6 complex signalling, was recently reported to not induce any activation of human platelets, but rather exerted inhibitory effects on platelets subsequently challenged with Pam3CSK4 [12]. Owing to these observations, and as the interplay between bacterial pathogens and human platelets is far from being fully understood, we have chosen to apply Pam3CSK4 instead of whole living bacteria or fragments to avoid any possible concealed opposing effects on TLR2/1 complex signalling.

However, it has further been shown that TLR2/1 activation induces phosphoinositide 3-kinase (PI3-K) activation [13], and that TLR2/1-mediated platelet activation and aggregation relies, besides other factors, on intermediate TXA2 signalling as well as P2Y/ADP receptor signalling. Although platelets were found to contain MyD88 and IRAK-1, the signalling cascade employed by TLR2/1 in immune cells obviously does not apply for human platelets [12]. We therefore investigated if the TLR2/1 complex may induce and utilize known 'platelet-specific' activatory pathways, such as those induced by physiological primary platelet agonists like collagen or thrombin. 
The subendothelial matrixprotein collagen mainly binds to the immunoglobulin receptor glycoprotein VI (GPVI), which via the src kinase family members Lyn and Fyn phosphorylates the immunoreceptor tyrosine-based activation motif (ITAM) of the cytoplasmic tail of the FcR $\gamma$-chain, followed by the recruitment of the spleen tyrosine kinase (Syk) which in turn phosphorylates the linker for activation of $\mathrm{T}$ cells (LAT), finally funneling into the activation of phospholipase C isoform $\gamma 2$ (PLC $\gamma 2$ ) [14]. As collagen may activate other platelet receptors besides GPVI, we applied within our study the snake venom toxin convulxin, a highly selective GPVI agonist [15].

Platelet activation via G protein-coupled receptors (GPCRs) is multiple orchestrated [16]. Thrombin, the major effector serine-protease of the coagulation cascade, provokes activation of human platelets via protease-activated receptors (PARs) 1 and 4 [17] which belong to the

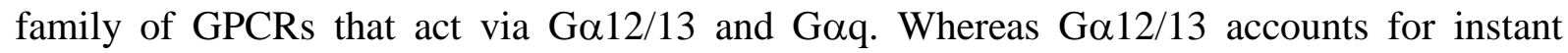
cytoskeletal reorganization (platelet 'shape change') via $\mathrm{Ca}^{2+} /$ calmodulin and Rho/Rho-kinase signalling, Gaq induces PLC isoform $\beta$ (PLC $\beta$ ) activation.

Both activated PLC $\beta$ and PLC $\gamma 2$ cleave phosphatidylinositol 4,5-bisphosphate (PIP2) into diacylglycerol (DAG) and inositol 1,4,5-trisphosphate (IP3). IP3 provokes the release of $\mathrm{Ca}^{2+}$ from intracellular stores that in concert with DAG induces activation of protein kinase $\mathrm{C}$ (PKC) which is strongly implicated in the secretion of platelet granules, such as dense granules which contain ATP and ADP. Furthermore, an increase in intracellular $\mathrm{Ca}^{2+}$ also accounts for the activation of phospholipase A2 (PLA2) leading to the liberation of arachidonic acid which is cyclooxygenase-dependently transformed into thromboxane A2 (TXA2). For TXA2 the thromboxane/prostanoid receptor $\alpha$ (TP $\alpha)$ is the predominant isoform

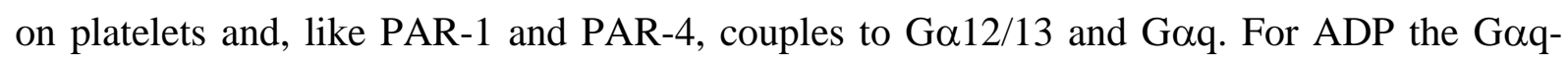
coupled P2Y1 receptors and Gai2-coupled P2Y12 receptors have been identified on platelets. The $\beta / \gamma$-subunit of Gai directly induces phosphatidylinositol 3-kinase (PI3-K) which amplifies granule secretion as well as activation of integrin $\alpha_{\text {IIa }} \beta_{3}$ ('inside-out' signalling) whereas the $\alpha$-subunit down-regulates adenylyl cyclase (AC) and therefore cyclic adenosine monophosphate (cAMP) levels, both which are pivotal for full and sustained platelet activation and aggregation. Hence, the Gai-coupled P2Y12 receptor plays a central role in the amplification of platelet activation and aggregation induced by all known platelet agonists so far regardless their initial signalling cascades employed, including collagen, thrombin, and TXA2 [18], as well as Pam3CSK4 [12]. 
Finally, fibrinogen-binding to activated integrin $\alpha_{\text {IIa }} \beta_{3}$, besides bridging platelets to form aggregates, also contributes to platelet activation and secretion by 'outside-in' signalling. By stimulating isolated human platelets with Pam3CSK4 we found that platelet TLR2/1 triggers the very signalling pathway excited by GPVI activation; involving src family kinases, Syk, and LAT phosphorylation, finally funneling into the activation of PLC $\gamma 2$ and $\mathrm{Ca}^{2+}$ mobilization. Unlike in some other 'classical' immune cells this cascade was not indirectly induced via $\beta_{3}$ integrins $[19,20]$ as demonstrated by the use of platelets from a patient with Glanzmann's thrombastenia lacking integrin $\beta_{3}$. Pam3CSK4-induced full platelet activation and secretion, similar to that triggered by the specific GPVI agonist convulxin, but not to that by thrombin, markedly relied on intermediate TXA2 signalling and finally, nonetheless, integrin $\alpha_{\mathrm{IIb}} \beta_{3}$ outside-in signalling.

\section{Material and Methods}

\subsection{Chemicals and antibodies}

The synthetic tripalmitylated lipopeptide Pam3CSK4 (N-Palmitoyl-S-[2,3-bis(palmitoyloxy)(2RS)-propyl]-[R]-cysteinyl-[S]-seryl-[S]-lysyl-[S]-lysyl-[S]-lysyl-[S]-lysine) was obtained from InvivoGen, convulxin from Pentapharm. Apyrase (Grade III, from potatoe), acetylsalicylic acid (aspirin), fura-2/AM (fura 2 acetoxymethylester), bovine thrombin (T4648), 2-MeS-ADP (2-methylthioadenosine-5'-o-diphosphate), as well as BAY61-3606 (2[[7-(3,4-Dimethoxyphenyl)imidazo[1,2-c]pyrimidin-5-yl]amino]pyridine-3-carboxamide hydrochloride) was from Sigma; PP2 (3-(4-chlorophenyl) 1-(1,1-dimethylethyl)-1Hpyrazolo[3,4- $d]$ pyrimidin-4-amine) and PP3 (1-Phenyl- $1 H$-pyrazolo[3,4- $d]$ pyrimidin-4amine), ICI 192,605 (4-(Z)-6-(2-o-Chlorophenyl-4-o-hydroxyphenyl-1,3-dioxan-cis-5yl)hexenoic acid) as well as CCCP (carbonyl cyanide 3-chlorophenylhydrazone) from Tocris. The Fab fragment of the chimeric human-murine monoclonal antibody 7E3 towards the platelet fibrinogen receptor abciximab $\left(\right.$ ReoPro $^{\circledR}$ ) was from Eli Lilly. The phospho-LAT (Tyr191) antibody (\#3584), the phospho-PLC $\gamma 2$ (Tyr759) (\#3874) and unmodified PLC $\gamma 2$ (\#3872) antibodies, as well as the HRP-conjugated secondary antibodies (\#7074 and \#7076) from Cell Signaling Technology, the $\beta$-tubulin antibody (clone AA2) (\#05-661) from Upstate/Millipore. All other reagents were of analytical grade.

\subsection{Isolation of human platelets}


Heparinized blood (10 IU/ml; LEO Pharma) was obtained from Linköping University Hospital's blood bank. Blood was transferred in a volumetric proportion of 5:1 to acid-citratedextrose (ACD: $71 \mathrm{mM}$ citric acid, $85 \mathrm{mM}$ sodium citrate, $111 \mathrm{mM}$ glucose) and centrifuged at $220 \mathrm{~g}$ for $20 \mathrm{~min}$. The platelet-rich plasma (PRP) obtained was subsequently centrifuged at $480 \mathrm{~g}$ for $25 \mathrm{~min}$. In experiments applying aspirin PRP was incubated with $100 \mu \mathrm{M}$ aspirin for 45 min prior to procession. Platelet pellets were carefully washed three times with KrebsRinger Glucose (KRG) buffer $(120 \mathrm{mM} \mathrm{NaCl}, 4.9 \mathrm{mM} \mathrm{KCl}, 1.2 \mathrm{mM} \mathrm{MgSO} 4,1.7 \mathrm{mM}$ $\mathrm{KH}_{2} \mathrm{PO}_{4}, 8.3 \mathrm{mM} \mathrm{Na} 2 \mathrm{HPO}_{4}, 10 \mathrm{mM}$ glucose; $\mathrm{pH}$ 7.3), and finally resupendend in $\mathrm{KRG}$ containing $0.05 \mathrm{U} / \mathrm{ml}$ apyrase. The platelet count was determined using an automatic blood cell counter (Micros 60 (ABX Diagnostics) and was adjusted to a final assay concentration of $2.5 \times 10^{8}$ platelets $/ \mathrm{ml}$. All isolation steps were carried out at room temperature (RT). Suspensions were supplemented with $1 \mathrm{mM} \mathrm{CaCl}_{2} 30 \mathrm{~min}$ prior to experimentation.

\subsection{Glanzmann's thrombasthenia patient}

With approval of the ethical board of Linköping's University and informed consent of both donors, venous blood from the patient and an age- and gender-matching healthy volunteer was drawn into syringes containing $10 \mathrm{IU} / \mathrm{ml}$ heparin, and platelets were isolated as described above. The patient, a young Swedish female, has been diagnosed as suffering from Glanzmann's thrombasthenia in 2003 by the Department of Haematology, Clinical Chemistry/Coagulation Unit, Karolinska Hospital, Stockholm, Sweden, due to a lack of integrin $\beta_{3}$; whereas the expression of GPIb was found to be normal. These results were routinely re-evaluated and fully confirmed in our lab at the day of blood-donation (all data were determined by flow cytometry).

\subsection{Platelet aggregation and ATP release}

Measurements were performed using a Chrono-Log dual channel lumi-aggregometer (Model 700 ) at $37^{\circ} \mathrm{C}$ with stirring at $900 \mathrm{rpm}$ within a final volume of $0.3 \mathrm{ml}$ platelet suspension. Aggregation is expressed as percentage light transmission compared to KRG alone (=100\%). Extracellular ATP was assessed applying a luciferin/luciferase bioluminescent assay and calculated using a provided ATP standard (all Chrono-Log).

\subsection{Immuno(western)blotting}

Stimulation of platelets were carried out at $37^{\circ} \mathrm{C}$ in a total volume of $0.2 \mathrm{ml}$ in $2 \mathrm{ml}$ roundbottom tubes in a thermoshaker rotating at $900 \mathrm{rpm}$; pre-incubations at $500 \mathrm{rpm}$. Reactions 
were stopped by the addition of $50 \mu \mathrm{l} 5 \mathrm{x}$ SDS sample buffer, and proteins were denaturated at $95^{\circ} \mathrm{C}$ for $5 \mathrm{~min}$. From these samples $25 \mu \mathrm{l}$ were applied for SDS-PAGE. For the detection of phosphorylated LAT proteins were separated on 4-12\% NuPAGE ${ }^{\circledR}$ Novex Bis-Tris gels with MOPS running buffer; for detecting phosphorylated PLC $\gamma 2$ proteins were separated on 3-8\% NuPAGE Tris-Acetate Gels and Tris-Acetate Running buffer (all Invitrogen). To determine apparent molecular protein masses MagicMark ${ }^{\mathrm{TM}}$ XP Western Protein Standard (Invitrogen) was used. Proteins were blotted onto Immun-Blot ${ }^{\mathrm{TM}}$ PVDF membranes $(0.2 \mu \mathrm{m})$ (BioRad, Hercules, CA, USA). For further steps TBS-T (10 mM Tris-HCl pH 8.0, $150 \mathrm{mM} \mathrm{NaCl}, 0.1 \%$ (w/v) Tween-20) was used. Membranes were incubated with the phospho-LAT antibody (diluted 1:2000) or phospho-PLC $\gamma 2$ (1:500) followed by peroxidase-conjugated goat antirabbit IgGs (1:2000). For re-probing membranes were stripped and incubated with either the $\beta$-tubulin antibody (1:1000) followed by peroxidase-coupled horse anti-mouse IgGs (1:2000), or the PLC $\gamma 2$ antibody (1:1000) followed by peroxidase-coupled goat anti-rabbit IgGs (1:2000). Protein bands were visualized by the use of Immobilon $^{\mathrm{TM}}$ Western Chemiluminescent HRP Substrate solution (Millipore), and chemiluminescence was recorded by a Fuji LAS 1000 system (Fuji Photo Film).

\subsection{Increase in cytosolic $\mathrm{Ca}^{2+}$}

Platelets were loaded with fura-2 by incubating PRP with $3 \mu \mathrm{M}$ fura-2/AM for $45 \mathrm{~min}$ at RT in the dark with gentle agitation and subsequently isolated as described above. Platelets were pre-incubated and stimulated as indicated at $37^{\circ} \mathrm{C}$ with stirring and fluorescence was recorded using a Hitachi F-7000 spectrofluorometer (Hitachi Ltd.) at $510 \mathrm{~nm}$ with simultaneous excitation at $340 \mathrm{~nm}$ and $380 \mathrm{~nm}$. Cytosolic calcium $\left[\mathrm{Ca}^{2+}\right]_{i}$ is expressed in fluorescence ratio $(340 / 380 \mathrm{~nm})$.

\subsection{Statistical analysis}

Data analysis was performed using Prism 4 software (GraphPad). Results are presented as mean \pm standard error of the mean (S.E.M.) and statistical analysis were calculated as indicated in the respective figure legend. 


\section{Results}

\subsection{Pam3CSK4 induces LAT and PLC $\gamma 2$ tyrosine phosphorylation in human platelets}

One eminent characteristic of collagen/convulxin-initiated platelet activation compared to that by thrombin or ADP is the prominent phosphorylation of the adaptor protein LAT [21-23]. Therefore, we initially investigated LAT Tyr191 phosphorylation by performing time-courses ranging from $5 \mathrm{sec}$ to $5 \mathrm{~min}$ applying relatively high agonist concentrations, i.e. $30 \mathrm{ng} / \mathrm{ml}$ convulxin, $10 \mu \mathrm{g} / \mathrm{ml}$ Pam3CSK4, $0.3 \mathrm{U} / \mathrm{ml}$ thrombin, as well as $100 \mu \mathrm{M}$ of the stable ADPanalogue 2-MeS-ADP.

As shown in Figure 1A, convulxin induces a rapid and transient LAT phosphorylation already detectable after $5 \mathrm{sec}$ of stimulation and peaking between 10 and 20 sec. Likewise, Pam3CSK4 induced phosphorylation of LAT that is also detectable after $5 \mathrm{sec}$ and peaks about $10 \mathrm{sec}$ after agonist-addition. In contrast, and as expected, $0.3 \mathrm{U} / \mathrm{ml}$ thrombin and 100 $\mu \mathrm{M}$ 2-MeS-ADP did not or only marginally provoke LAT phosphorylation.

Owing to these results, and as LAT serves as an adaptor protein that mediates cellular signalling but lacks enzymatic activity, we next evaluated the phosphorylation of PLC $\gamma 2$, which is the major effector of GPVI-mediated platelet activation. As shown in Figure 1B, we found that both convulxin $(30 \mathrm{ng} / \mathrm{ml})$ and Pam3CSK4 $(10 \mu \mathrm{g} / \mathrm{ml})$, following the time-course of LAT phosphorylation, induced rapid and transient phosphorylation of PLC $\gamma 2$ at tyrosine 579 residues.

3.2. Pam3CSK4 provokes LAT and PLC $\gamma 2$ phosphorylation as well as cytosolic $\mathrm{Ca}^{2+}$ mobilization in a src family kinases- and Syk-dependent manner

It is well established that cross-linking of GPVI by collagen or convulxin induces tyrosine phosphorylation of the immunoreceptor tyrosine-based activation motif (ITAM) of the cytoplasmic tail of the FcR $\gamma$-chain via the src kinases Lyn and Fyn followed by the recruitment of Syk, the latter which in turn phosphorylates LAT [24].

To investigate whether Pam3CSK4-evoked platelet activation is also mediated via these signalling molecules we pretreated platelets with the commonly applied src-family inhibitor PP2 $(10 \mu \mathrm{M})$, its inactive analogue PP3 $(10 \mu \mathrm{M})$, as well as the potent and highly selective Syk-inhibitor BAY 61-3606 at $1 \mu \mathrm{M}$. In this and the following sets of experiments we applied more moderate agonist-concentrations to augment the susceptibility of platelet signalling mediators towards pharmacological inhibitors. 
Regarding LAT, as demonstrated in Figure 2A, we observed that Tyr191 phosphorylation provoked by $7.5 \mu \mathrm{g} / \mathrm{ml}$ Pam3CSK4 was completely abolished by $10 \mu \mathrm{M}$ PP2, but, as expected, not or only slightly by PP3. BAY 61-3606 at $1 \mu \mathrm{M}$ also abrogated Pam3CSK4induced LAT Tyr191 phosphorylation, and likewise almost fully blocked the response to 7.5 $\mathrm{ng} / \mathrm{ml}$ convulxin. Neither PP2 or PP3, nor the BAY-compound alone had any effect on basal LAT Tyr191 phosphorylation.

Evaluating PLC $\gamma 2$ activation (Figure 2B) revealed that Tyr759 phosphorylation induced by Pam3CSK4 was consequently likewise inhibited by PP2 and the BAY-compound, the latter which also effectively prevented convulxin-excited PLC $\gamma 2$ Tyr759 phosphorylation.

We further assessed cytosolic $\mathrm{Ca}^{2+}$-mobilization, recognized as probably the most sensitive marker for platelet activation. As shown in Figure 2C, PP2 fully abolished $\mathrm{Ca}^{2+}$-mobilization induced by Pam3CSK4, whereas PP3 had no effect. Furthermore, BAY 61-3606 also completely abrogated Pam3CSK4-evoked $\mathrm{Ca}^{2+}$-mobilization. By contrast, the BAYcompound had no effect on $\mathrm{Ca}^{2+}$-mobilization induced by $10 \mu \mathrm{M}$ 2-MeS-ADP, which evokes $\mathrm{Ca}^{2+}$-mobilization selectively via Gaq-coupled P2Y1 receptors [18].

\subsection{The Syk inhibitor BAY 61-3606 concentration-dependently abolishes Pam3CSK4- evoked platelet dense granule secretion and aggregation}

In addition to the intracellular events reported above, we next investigated the role of Syk in Pam3CSK4-promoted platelet responses such as dense granule secretion and, as ultimate functional consequence, aggregation. As shown in Figure 3, BAY 61-3606 concentrationdependently (applied from 0.25 up to $1 \mu \mathrm{M}$ ) abrogated ATP release evoked by $7.5 \mu \mathrm{g} / \mathrm{ml}$ Pam3CSK4, and consequently markedly, albeit not completely, platelet aggregation. Furthermore, the BAY-compound at $1 \mu \mathrm{M}$ entirely precluded ATP release and platelet aggregation in response to $7.5 \mathrm{ng} / \mathrm{ml}$ convulxin. In contrast, neither platelet ATP release nor aggregation in response to $0.1 \mathrm{U} / \mathrm{ml}$ thrombin was affected by BAY 61-3606.

\subsection{Platelet dense granule secretion and aggregation in response to Pam3CSK4 strongly} relies on intermediate TXA2 signalling and integrin $\alpha_{\text {IIa }} \beta_{3}$ outside-in signalling

Collagen-induced platelet dense granule secretion and aggregation markedly rely on intermediate TXA2 signalling, whereas this dependency accounts for convulxin-provoked platelet activation at low but not high agonist-concentrations [25, 26].

By precluding TXA2 signalling by either preventing its synthesis with aspirin $(100 \mu \mathrm{M})$ or by pretreatment with the TP $\alpha$ receptor antagonist ICI 192,605 $(5 \mu \mathrm{M})$ we found that platelet 
dense granule secretion induced by both $7.5 \mu \mathrm{g} / \mathrm{ml}$ Pam3CSK4 and $7.5 \mathrm{ng} / \mathrm{ml}$ convulxin was almost completely abolished (Figure 4A) and consequently aggregation prominently inhibited (Figure 4B). In contrast, although both aspirin and ICI 192,605 pretreatment significantly attenuated dense granule secretion caused by $0.1 \mathrm{U} / \mathrm{ml}$ thrombin about $53 \%$ and $41 \%$, respectively, the extent of platelet aggregation was not affected, indicating that the amount of released ADP was sufficient for full platelet aggregation.

With respect to TXA2 signalling, it has been demonstrated that the stable TXA2-mimetic U46619 induces two distinct waves of platelet dense granule secretion, and that the second wave is abrogated when either P2Y12 receptor- or integrin $\alpha_{\text {IIa }} \beta_{3}$ outside-in-signalling is precluded $[27,28]$. Along this line, we assessed the impact of integrin $\alpha_{\text {IIa }} \beta_{3}$ outside-in signalling by preventing fibrinogen-binding with the monoclonal antibody abciximab (Figure 5). In abciximab-preincubated platelets dense granule secretion in response to Pam3CSK4 $(7.5 \mu \mathrm{g} / \mathrm{ml})$ and convulxin $(7.5 \mathrm{ng} / \mathrm{ml})$, but not to thrombin $(0.1 \mathrm{U} / \mathrm{ml})$, was substantially diminished (Figure 5A). This was found not to be due to a general impairment of dense granule secretion, as platelets released prominent and almost normal amounts of ATP $(\sim 3$ $\mu \mathrm{M}$ ) when subsequently challenged with $0.1 \mathrm{U} / \mathrm{ml}$ thrombin. Under all tested conditions platelet aggregation, as expected, was prominently precluded by abciximab (Figure 5B)

\subsection{Pam3CSK4 induces LAT and PLC $\gamma 2$ phosphorylation as well as cytosolic $\mathrm{Ca}^{2+}$ - mobilization in platelets from a patient with Glanzmann's thrombasthenia}

Interestingly, and with respect to the results shown above, TLR signalling in other cell types of the immune system may integrate or markedly rely on ITAM-bearing receptors such as FcRs or $\beta$ integrins for PLC $\gamma$ activation and, in turn, $\mathrm{Ca}^{2+}$ and DAG signalling (for review see [19]). Using isolated platelets from a Glanzmann's thrombasthenia patient (Figure 6) we found that convulxin $(7.5 \mathrm{ng} / \mathrm{ml})$ as well as Pam3CSK4 $(7.5$ and $30 \mu \mathrm{g} / \mathrm{ml})$ evoked both LAT Tyr191 and PLC 22 Tyr759 phosphorylation (Figure 6A). Accordingly, mobilization of cytosolic $\mathrm{Ca}^{2+}$ in response to Pam3CSK4 was not impaired in Glanzmann's thrombasthenia platelets compared with control platelets (Figure 6B).

Regarding platelet dense granule secretion and aggregation we observed relatively normal extents of ATP release provoked by $7.5 \mu \mathrm{g} / \mathrm{ml}$ Pam3CSK4, $7.5 \mathrm{ng} / \mathrm{ml}$ convulxin, and 0.1 $\mathrm{U} / \mathrm{ml}$ thrombin resulting in full aggregation of control platelets (Figure 7A and B). In sharp contrast, especially with respect to proper LAT and PLC $\gamma 2$ phosphorylation, as well as cytosolic $\mathrm{Ca}^{2+}$ mobilization (Figure 6A and B), neither Pam3CSK4 nor convulxin elicited any ATP release from the Glanzmann's thrombasthenia platelets (Figure 7A). Similar to the 
observation shown in Figure 5A, when platelets from the Glanzmann's thrombasthenia patient where subsequently challenged with $0.1 \mathrm{U} / \mathrm{ml}$ thrombin almost normal amounts of ATP were secreted. Finally, although rather needless to mention, Glanzmann's thrombasthenia platelets failed to aggregate under any applied condition (Figure 7B).

\subsection{Pam3CSK4 does not induce GPVI signalling}

As we so far found that Pam3CSK4-evoked intracellular events and functional consequences resemble those of GPVI-mediated platelet activation and aggregation, it is tempting to speculate that Pam3CSK4 may simply cross-react with GPVI.

To preclude GPVI signalling we pretreated platelets with a low concentration of convulxin $(1.0 \mathrm{ng} / \mathrm{ml})$ in order to induce GPVI desensitization [29] and/or shedding off its ectodomain by the metalloproteinase ADAM10 [30] (Figure 8A). Alternatively we induced activationindependent shedding via inducing ADAM17 by causing mitochondrial damage applying carbonylcyanide m-chlorophenylhydrazon (CCCP) [30, 31] (Figure 8B).

In low-dose $(1 \mathrm{ng} / \mathrm{ml})$ convulxin-pretreated platelets aggregation in response to subsequently added $7.5 \mathrm{ng} / \mathrm{ml}$ convulxin was almost completely abrogated, whereas that to Pam3CSK4 was unaffected (Figure 8A). In CCCP-preincubated platelets the response to convulxin, even when applied up to $500 \mathrm{ng} / \mathrm{ml}$, was nullified, whereas that provoked by Pam3CSK was slightly, but not significantly, reduced (Figure 8B). Although merely speculative, we assume that this minor effect of CCCP may be attributed to its toxic cyanide-motif. CCCP alone had no effect on platelet aggregation (data not shown).

\section{Discussion}

The discovery that human platelets are sensitive to microbial pathogens and express Toll-like receptors shed a new light on these small and non-nucleated cells as components of the innate immune system. A broad variety of proteins involved in TLR signalling in nucleated cells has been likewise detected in platelets, including MyD88 and IRAK-1 [12, 32]. Whereas it has been shown that human platelet TLR4 signalling engages MyD88 [33], TLR2/1 activation by Pam3CSK4 was reported to not induce IRAK-1 phosphorylation [12]. Although several former studies demonstrated that the bacterial lipopeptide-mimicking TLR2/1-heterodimer agonist Pam3CSK4 concentration-dependently triggers prominent platelet activation and full aggregation [11-13], the underlying initial signalling pathway, however, has not been defined in detail so far. 
Platelet activation induced by thrombin via PARs or collagen via GPVI involves phosphorylation and therefore activation of PLC isoforms $\beta$ and $\gamma 2$, respectively, and it has previously been reported that the pan-PLC inhibitor U73122 markedly attenuated secretion and aggregation of Pam3CSK4-stimulated human platelets [12]. Whereas the adaptor protein LAT is strictly involved in GPVI-mediated PLC $\gamma 2$ phosphorylation and downstream PKC activation, LAT phosphorylation induced via GPCRs such as PARs or P2Y receptors has been reported to be only marginal. We observed that Pam3CSK4, in common with the GPVI agonist convulxin, provoke rapid, prominent, and transient phosphorylation of LAT at tyrosine 191 residues, the latter which has been demonstrated to be essential for coupling multiple signalling molecules $[34,35]$. In contrast, thrombin and 2-MeS-ADP, as expected, had no or only weak effects on LAT tyrosine phosphorylation. However, and in consequence, we found that Pam3CSK4 promoted marked PLC $\gamma 2$ phosphorylation at Tyr759 residues, the latter which has been reported to be associated with human platelet activation in response to collagen [36].

The initial steps of the GPVI-induced signalling cascade are accomplished by the phosphorylation of the ITAM motif of the FcR $\gamma$-chain by the src-family kinase members Lyn and Fyn [37, 38] followed by Syk-mediated phosphorylation of the adaptor protein LAT [21, 39]. In line with a previous study, showing the inhibition of convulxin-induced Syk and PLC $\gamma 2$ tyrosine phosphorylation as well platelet aggregation by the src family inhibitor PP1 [38], we found that src kinase inhibition by closely related PP2 abolished convulxin- and likewise Pam3CSK4-triggered tyrosine phosphorylation of LAT and PLC 2 , as well as intracellular $\mathrm{Ca}^{2+}$ mobilization, and, finally, platelet aggregation (data not shown). Similar results were obtained when Syk was inhibited, demonstrating that activation of platelets via TLR2/1 with Pam3CSK4, in common with GPVI-mediated platelet excitation, is initiated via the src/Syk/LAT/PLC $\gamma 2$ signalling cascade.

It may be worth mentioning regarding interfering with Syk-mediated signalling that we in this study applied BAY 61-3606 instead of the still widely applied Syk inhibitor piceatannol, which is known to exhibit unspecific effects on, for instance, other tyrosine kinases [40], and in our hands markedly interfered with the luciferin/luciferase reagent used for measuring platelet ATP secretion (Magnus Grenegård, unpublished observation). BAY 61-3606 has been developed as an orally available Syk inhibitor and shown to be highly selective for Syk over other tyrosine kinases including Fyn and Lyn [41], and in our study concentrationdependently decreased Pam3CSK4-induced dense granule secretion as well as platelet aggregation. In addition, the BAY-compound applied at $1 \mu \mathrm{M}$ completely abolished 
mentioned platelet responses provoked by $7.5 \mu \mathrm{g} / \mathrm{ml}$ convulxin, but had no effect on platelets stimulated with $0.1 \mathrm{U} / \mathrm{ml}$ thrombin or $10 \mu \mathrm{M}$ 2-MeS-ADP.

By the use of aspirin the involvement of intermediate TXA2 signalling in Pam3CSK4triggered platelet dense granule secretion and aggregation has been shown before [12]. The direct comparison of the three agonists applied within our study revealed that Pam3CSK4and convulxin-promoted dense granule secretion and aggregation were almost completely inhibited by either precluding TXA2 synthesis with aspirin or by blocking the TP $\alpha$ receptor with ICI 192,605, whereas the responses evoked by thrombin via PARs and Gq signalling were only partially affected.

Notably, it has been demonstrated that the TXA2-mimetic U46619 induces a biphasic course of dense granule secretion and aggregation of aspirinated platelets, and that the second wave of secretion and full aggregation is completely absent when either $\alpha_{\text {IIa }} \beta_{3}$ outside-in or P2Y12 receptor signalling was precluded $[27,28]$. When we mimicked the lack of integrin $\beta_{3}$ signalling by precluding fibrinogen-binding and integrin $\alpha_{\text {IIa }} \beta_{3}$ outside-in signalling with abciximab we observed a similar lack of Pam3CSK4- and convulxin-provoked dense granule secretion. Along this line, a most interesting aspect of TLR-induced cell activation is the integration and even orchestration of ITAM-associated receptors such as Fc receptors or $\beta_{2}$ and $\beta_{3}$ integrins to simultaneously activate PLC $\gamma$-mediated pathways [19]. In this context, in monocytes from Glanzmann's thrombasthenia patients lacking $\beta_{3}$ integrins it has been shown that Pam3CSK4-provoked production of TNF and IL-8 completely relied on concomitant signalling via the vitronectin-receptor integrin $\alpha_{V} \beta_{3}[20]$.

Using platelets from a Glanzmann's thrombasthenia patient stimulated with Pam3CSK4 we observed proper tyrosine phosphorylation of LAT and PLC $\gamma 2$, as well as intracellular $\mathrm{Ca}^{2+}$ mobilization, demonstrating that these responses are directly induced via TLR2/1 and not indirectly via $\beta_{3}$ integrin activation and subsequent outside-in signalling. On the other hand, both Pam3CSK4- as well as convulxin-promoted dense granule secretion was absent in the Glanzmann's thrombasthenia patient platelets. Together these findings demonstrate that integrin $\beta_{3}$ signalling is not involved in the initiation of platelet activation via TLR2/1, but is nonetheless necessarily required for subsequent platelet dense granule secretion in response to Pam3CSK. In addition, and with respect to the marked phosphorylation of LAT determined in Pam3CSK4-treated platelets, it has been shown that LAT is not involved in $\alpha_{\text {IIa }} \beta_{3}$ outside-in signalling mediated PLC $\gamma 2$ activation and $\mathrm{Ca}^{2+}$-mobilization [42]. 
It has recently been demonstrated that Pam3CSK4 promotes platelet PI3-K activation and, interestingly, a biphasic phosphorylation of the PI3-K downstream serine/threonine kinase Akt has been observed [13, 43]. In human platelets PI3-K becomes activated by either the initial stimulatory pathway or, and even more prominently, via released ADP and secondary P2Y12 receptor signalling. Along this line, it has been shown that phosphorylated LAT associates, besides a number of other proteins such as Grb2, SLP-76, and PLC $\gamma 2$, with the regulatory p85 subunit of PI3-K [21], and that Pam3CSK4-provoked platelet activation and aggregation strongly rely on released ADP and P2Y12 signalling [12]. Hence, the two waves of Akt phosphorylation by PI3-K may be explained by initial LAT-mediated signalling, leading to dense granule secretion, and subsequent P2Y12 signalling.

In this context we may propose the following simplified sequence of Pam3CSK4-induced platelet activation and aggregation: TLR2/1 signalling provokes via PLC $\gamma 2$ an increase in $\mathrm{Ca}^{2+}$ that, besides triggering PKC and granules secretion, induces activation of PLA2 and subsequent TXA2 generation. Released TXA2 enhances via Gq-coupled TP $\alpha$ receptors and PLC $\beta$ dense granule secretion, the latter which is finally strongly amplified by either P2Y12 signalling and/or outside-in signalling of integrin $\alpha_{\mathrm{IIb}} \beta_{3}$.

So far, as Pam3CSK4-initiated platelet activation appears identical to that induced by GPVI, one might argue that Pam3CSK4, besides its proposed TLR2/1 receptor-complex target, may also activate GPVI. When we depleted GPVI from the platelet surface by unrelated experimental strategies [29-31] aggregation induced by convulxin was abolished, whereas the response to Pam3CSK4 was unaltered, demonstrating that Pam3CSK4-provoked human platelet activation and aggregation is not driven by GPVI cross-activation. Along this line, it has previously been shown that Pam3CSK4-induced aggregation of human platelets was markedly inhibited by the pretreatment with a functional monoclonal TLR2 antibody, and that aggregation of murine TLR $2^{-/-}$platelets challenged with Pam3CSK4 was strongly impaired [13]. Especially this latter finding clearly underlines the specificity of Pam3CSK4 for TLR2. However, albeit most studies so far concentrated on the well-defined TLR2/1 signalling pathway involving MyD88 and IRAK-1, it has been demonstrated in airway epithelial cell lines and macrophages treated with Pam3CSK4 that src family kinases conduct TLR2associated signalling by the recruitment of PI3K and PLC $\gamma$ to mediate the release of $\mathrm{Ca}^{2+}$ from intracellular stores, thereby promoting $\mathrm{Ca}^{2+}$-related downstream signalling [44]. Furthermore, in human neutrophils it has been found that TLR2 signalling induced Rac2 and Cdc42 activation [45]. Along this line, activation of TLR2 on the monocytic cell line THP1 has been reported to lead to a rapid and transient activation of Rac1 and Cdc42, and a 
signalling cascade composed of Rac1, PI3-K, and Akt inducing subsequent NF-kB transcriptional activity has been proposed [46]. With respect to platelets, it has been demonstrated in a mouse knock-out model that Rac1 is essential for ITAM-mediated GPVIinduced activation of PLC $\gamma 2$ [47].

Although the ITAM-bearing adaptor for TLR2/1 in human platelets remains to be elucidated, our study indicates that the TLR2/1 complex may be added to the set of platelet immunereceptors that initiate platelet excitation via the src/Syk/LAT/PLC $\gamma 2$ pathway.

Clinical studies revealed that bacterial infections are associated with a transient increase in the risk of severe thrombotic events such as myocardial infarction or stroke [48]. In addition, platelets are also critically involved in the pathophysiology of sepsis [49] and systemic platelet activation due to bacterial infections augments the degree of thrombocytopenia and, hence, the severity of sepsis [50]. Anti-thrombotic drugs, such as cyclooxygenase-inhibitors or P2Y12- and integrin $\alpha_{\text {IIa }} \beta_{3}$-antagonists have been shown to be beneficial under septic conditions [51], and may also, in line with previous and our observations, being considered to prevent bacteria-related thrombotic events.

\section{Conclusions}

5.1. Pam3CSK4-evoked TLR2/1 signalling initiates human platelet activation via the src/Syk/LAT/PLC $\gamma 2$ signalling pathway.

\subsection{Pam3CSK4 does not cross-activate GPVI}

5.3. Pam3CSK4-provoked platelet activation strongly relies on intermediate TXA2- as well as subsequent integrin $\alpha_{\text {IIa }} \beta_{3}$-signalling.

5.4. In contrast to some other cells of the immune system, human platelet activation provoked by TLR2/1 signalling does initially not involve integrin $\beta_{3}$ signalling.

\section{Contributions}

K.F., K.K-E., and M.G. designed the experiments, and performed research and data analysis. T.B. and T.L. provided critical input and helpful discussion, and contributed to the experimental design. K.F. and M.G. interpreted results, directed the research, and drafted the manuscript; K.F. wrote the manuscript. 


\section{Conflict of interest}

None to declare.

\section{Acknowledgments}

The authors thank Dr. Sofia Ramström for re-evaluating the expression of integrin $\beta_{3}$ and GPIb on the Glanzmann's thrombasthenia patient platelets.

This work was supported by the Swedish Research Council (project numbers K2009-65X21178-01-3, K2010-65X-15060-07-3, and K2013-65X-15060-10-3), the Swedish Heart Lung Foundation (project number 20110632), the Foundation of Olle Engkvist, as well as by the Medical Faculty of the University of Linköping through Forsknings- och Forskarutbildningsnämnden (FUN).

\section{References}

[1] Brewer DB. British Journal of Haematology 133 (2006) 251-258.

[2] Elzey BD, Sprague DL, Ratliff TL. Cellular Immunology 238 (2005) 1-9.

[3] Cox D, Kerrigan SW, Watson SP. Journal of Thrombosis and Haemostasis 9 (2011) 1097-1107.

[4] Semple JW, Italiano JE, Jr., Freedman J. Nature Reviews Immunology 11 (2011) 264274.

[5] Shiraki R, Inoue N, Kawasaki S, Takei A, Kadotani M, Ohnishi Y, Ejiri J, Kobayashi S, Hirata K-i, Kawashima S, Yokoyama M. Thrombosis Research 113 (2004) 379-385.

[6] Cognasse F, Hamzeh H, Chavarin P, Acquart S, Genin C, Garraud O. Immunology and Cellular Biology 83 (2005) 196-198.

[7] Aslam R, Speck ER, Kim M, Crow AR, Bang KW, Nestel FP, Ni H, Lazarus AH, Freedman J, Semple JW. Blood 107 (2006) 637-641.

[8] Ozinsky A, Underhill DM, Fontenot JD, Hajjar AM, Smith KD, Wilson CB, Schroeder L, Aderem A. Proceedings of the National Academy of Sciences of the United States of America 97 (2000) 13766-13771.

[9] Wyllie DH, Kiss-Toth E, Visintin A, Smith SC, Boussouf S, Segal DM, Duff GW, Dower SK. Journal of Immunology 165 (2000) 7125-7132.

[10] Takeda K, Akira S. International Immunology 17 (2005) 1-14.

[11] Berg M, Offermanns S, Seifert R, Schultz G. American Journal of Physiology 266 (1994) C1684-1691.

[12] Kälvegren H, Skoglund C, Helldahl C, Lerm M, Grenegård M, Bengtsson T. Thrombosis and Haemostasis 103 (2010) 398-407.

[13] Blair P, Rex S, Vitseva O, Beaulieu L, Tanriverdi K, Chakrabarti S, Hayashi C, Genco CA, Iafrati M, Freedman JE. Circulation Research 104 (2009) 346-354.

[14] Kasirer-Friede A, Kahn ML, Shattil SJ. Immunological Reviews 218 (2007) 247-264.

[15] Polgar J, Clemetson JM, Kehrel BE, Wiedemann M, Magnenat EM, Wells TN, Clemetson KJ. Journal of Biological Chemistry 272 (1997) 13576-13583.

[16] Offermanns S. Circulation Research 99 (2006) 1293-1304.

[17] Kahn ML, Nakanishi-Matsui M, Shapiro MJ, Ishihara H, Coughlin SR. Journal of Clinical Investigation 103 (1999) 879-887. 
[18] Gachet C. Thrombosis and Haemostasis 99 (2008) 466-472.

[19] Ivashkiv LB. Nature Immunology 10 (2009) 340-347.

[20] Gerold G, Ajaj KA, Bienert M, Laws HJ, Zychlinsky A, de Diego JL. Nature Immunology 9 (2008) 761-768.

[21] Gibbins JM, Briddon S, Shutes A, van Vugt MJ, van de Winkel JGJ, Saito T, Watson SP. Journal of Biological Chemistry 273 (1998) 34437-34443.

[22] Asazuma N, Wilde JI, Berlanga O, Leduc M, Leo A, Schweighoffer E, Tybulewicz V, Bon C, Liu SK, McGlade CJ, Schraven B, Watson SP. Journal of Biological Chemistry 275 (2000) 33427-33434.

[23] Sarkar S. FEBS Letters 441 (1998) 357-360.

[24] Wonerow P, Watson SP. Oncogene 20 (2001) 6273-6283.

[25] Atkinson BT, Stafford MJ, Pears CJ, Watson SP. European Journal of Biochemistry 268 (2001) 5242-5248.

[26] Quinton TM, Özdener F, Dangelmaier C, Daniel JL, Kunapuli SP. Blood 99 (2002) 3228-3234.

[27] Li Z, Zhang G, Le Breton GC, Gao X, Malik AB, Du X. Journal of Biological Chemistry 278 (2003) 30725-30731.

[28] Elvers M, Grenegård M, Khoshjabinzadeh H, Münzer P, Borst O, Tian H, Di Paolo G, Lang F, Gawaz M, Lindahl TL, Fälker K. Cellular Signalling 24 (2012) 1743-1752.

[29] Vargaftig BB, Joseph D, Wal F, Marlas G, Chignard M, Chevance LG. European Journal of Pharmacology 92 (1983) 57-68.

[30] Gardiner EE, Karunakaran D, Shen Y, Arthur JF, Andrews RK, Berndt MC. Journal of Thrombosis and Haemostasis 5 (2007) 1530-1537.

[31] Bergmeier W, Rabie T, Strehl A, Piffath CL, Prostredna M, Wagner DD, Nieswandt B. Thrombosis and Haemostasis 91 (2004) 951-958.

[32] Berthet J, Damien P, Hamzeh-Cognasse H, Pozzetto B, Garraud O, Cognasse F. British Journal of Haematology 151 (2010) 89-92.

[33] Zhang G, Han J, Welch EJ, Ye RD, Voyno-Yasenetskaya TA, Malik AB, Du X, Li Z. Journal of Immunology 182 (2009) 7997-8004.

[34] Zhang W, Trible RP, Zhu M, Liu SK, McGlade CJ, Samelson LE. Journal of Biological Chemistry 275 (2000) 23355-23361.

[35] Paz PE, Wang S, Clarke H, Lu X, Stokoe D, Abo A. Biochemical Journal 356 (2001) 461-471.

[36] Özdener F, Dangelmaier C, Ashby B, Kunapuli SP, Daniel JL. Molecular Pharmacology 62 (2002) 672-679.

[37] Suzuki-Inoue K, Tulasne D, Shen Y, Bori-Sanz T, Inoue O, Jung SM, Moroi M, Andrews RK, Berndt MC, Watson SP. Journal of Biological Chemistry 277 (2002) 2156121566.

[38] Ezumi Y, Shindoh K, Tsuji M, Takayama H. Journal of Experimental Medicine 188 (1998) 267-276.

[39] Pasquet JM, Gross B, Quek L, Asazuma N, Zhang W, Sommers CL, Schweighoffer E, Tybulewicz V, Judd B, Lee JR, Koretzky G, Love PE, Samelson LE, Watson SP. Molecular and Cellular Biology 19 (1999) 8326-8334.

[40] Law DA, Nannizzi-Alaimo L, Ministri K, Hughes PE, Forsyth J, Turner M, Shattil SJ, Ginsberg MH, Tybulewicz VL, Phillips DR. Blood 93 (1999) 2645-2652.

[41] Yamamoto N, Takeshita K, Shichijo M, Kokubo T, Sato M, Nakashima K, Ishimori M, Nagai H, Li Y-F, Yura T, Bacon KB. Journal of Pharmacology and Experimental Therapeutics 306 (2003) 1174-1181.

[42] Wonerow P, Obergfell A, Wilde JI, Bobe R, Asazuma N, Brdicka T, Leo A, Schraven B, Horejsi V, Shattil SJ, Watson SP. Biochemical Journal 364 (2002) 755-765. 
[43] Rex S, Beaulieu LM, Perlman DH, Vitseva O, Blair PS, McComb ME, Costello CE, Freedman JE. Thrombosis and Haemostasis 102 (2009) 97-110.

[44] Chun J, Prince A. Journal of Immunology 177 (2006) 1330-1337.

[45] Borgeson E, Lonn J, Bergstrom I, Brodin VP, Ramstrom S, Nayeri F, Sarndahl E, Bengtsson T. Infection and Immunity 79 (2011) 1489-1497.

[46] Arbibe L, Mira JP, Teusch N, Kline L, Guha M, Mackman N, Godowski PJ, Ulevitch RJ, Knaus UG. Nature Immunology 1 (2000) 533-540.

[47] Pleines I, Elvers M, Strehl A, Pozgajova M, Varga-Szabo D, May F, ChrostekGrashoff A, Brakebusch C, Nieswandt B. Pflugers Archiv - European Journal of Physiology 457 (2009) 1173-1185.

[48] Smeeth L, Thomas SL, Hall AJ, Hubbard R, Farrington P, Vallance P. New England Journal of Medicine 351 (2004) 2611-2618.

[49] Vincent JL, Yagushi A, Pradier O. Critical Care Medicine 30 (2002) S313-317.

[50] Mavrommatis AC, Theodoridis T, Orfanidou A, Roussos C, Christopoulou-Kokkinou V, Zakynthinos S. Critical Care Medicine 28 (2000) 451-457.

[51] Lösche W, Boettel J, Kabisch B, Winning J, Claus RA, Bauer M. Thrombosis 2012 (2012) 720254. 


\section{Figure legends}

Figure 1. Pam3CSK4 induces rapid and transient LAT and PLC $\gamma 2$ tyrosine phosphorylation in human platelets

Isolated human platelets were pre-warmed to $37^{\circ} \mathrm{C}$ with gentle rotating at $500 \mathrm{rpm}$ and then stimulated with buffer or $30 \mathrm{ng} / \mathrm{ml}$ convulxin, $10 \mathrm{mg} / \mathrm{ml}$ Pam3CSK4, $0.3 \mathrm{U} / \mathrm{ml}$ thrombin, or $100 \mu \mathrm{M} 2-\mathrm{MeS}$-ADP for the times indicated at $37^{\circ} \mathrm{C}$ with rotating at $900 \mathrm{rpm}$. Reactions were stopped by the addition of SDS-sample buffer. Samples were analyzed by SDS-PAGE followed by Western blotting as described in "Material and Methods" using antibodies recognizing (A) LAT phosphorylated at Tyr191 residues and unmodified $\beta$-tubulin or (B) PLC $\gamma 2$ phosphorylated at Tyr759 residues and unmodified PLC $\gamma 2$. The blots shown in (A) are from one experiment that is representative of four independent experiments respectively. For (B) samples from the above experiments were in equal parts pooled and subjected to the SDSPAGE and Western blotting procedure.

Figure 2. Pam3CSK4 provoked LAT and PLC $\gamma 2$ phosphorylation as well as cytosolic $\mathrm{Ca}^{2+}$ mobilization is mediated via src kinases and Syk

For A and B: Isolated human platelets were preincubated with vehicle, $10 \mu \mathrm{M}$ PP2, $10 \mu \mathrm{M}$ $\mathrm{PP} 3$, or $1 \mu \mathrm{M}$ BAY 61-3606 (BAY) (all samples contain $0.05 \%$ DMSO) for $5 \mathrm{~min}$ at $37^{\circ} \mathrm{C}$ with gentle rotating at $500 \mathrm{rpm}$ and stimulated with buffer, $7.5 \mathrm{mg} / \mathrm{ml} \mathrm{Pam} 3 \mathrm{CSK} 4$, or 7.5 $\mathrm{ng} / \mathrm{ml}$ convulxin for $10 \mathrm{sec}$ at $37^{\circ} \mathrm{C}$ with and rotating at $900 \mathrm{rpm}$. Reactions were stopped by the addition of SDS-sample buffer. Samples were analyzed by SDS-PAGE followed by Western blotting as described in "Material and Methods" using antibodies recognizing (A) LAT phosphorylated at Tyr191 residues and unmodified $\beta$-tubulin or (B) PLC $\gamma 2$ phosphorylated at Tyr759 residues and unmodified PLC $\gamma 2$. The result shown in (A) is from one experiment that is representative of three independent experiments. For (B) samples from the above experiments were in equal parts pooled and subjected to the SDS-PAGE and Western blotting procedure. C: Maximal peak rises in cytosolic $\mathrm{Ca}^{2+}$ under indicated conditions were determined as described in "Material and Methods". Isolated platelets were incubated with vehicle, $10 \mu \mathrm{M}$ PP2, $10 \mu \mathrm{M}$ PP3, or $1 \mu \mathrm{M}$ BAY $61-3606$ for 5 min at $37^{\circ} \mathrm{C}$ and stimulated with buffer, $7.5 \mu \mathrm{g} / \mathrm{ml}$ Pam3CSK4 (all samples contain 0.05\% DMSO), or 10 $\mu \mathrm{M}$ 2-MeS-ADP (samples do not contain DMSO). Data of three individual experiments is presented as mean \pm S.E.M. and statistical analysis was performed by two-tailed paired Student's $t$ tests; ${ }^{*} \mathrm{P}<0.05$, ns $=$ not significant. 
Figure 3. The Syk-inhibitor BAY 61-3606 concentration-dependently abolish Pam3CSK4-induced platelet dense granule secretion and aggregation

Platelet ATP release (A) and aggregation (B) were determined in parallel as described in "Material and Methods". Isolated human platelets were incubated with buffer or BAY 613606 (BAY) at indicated concentrations for $5 \mathrm{~min}$ at $37^{\circ} \mathrm{C}$ with stirring at $900 \mathrm{rpm}$ prior to the addition of $7.5 \mu \mathrm{g} / \mathrm{ml} \mathrm{Pam3CSK} 4,7.5 \mathrm{ng} / \mathrm{ml}$ convulxin, or $0.1 \mathrm{U} / \mathrm{ml}$ thrombin. The bar graphs show maximal ATP release (in $\mu \mathrm{M}$ ) and aggregation assessed after 10 min of stimulation (in $\%$ light transmission). Data is presented as mean \pm S.E.M. and statistical analysis were performed by 1way ANOVA followed by Bonferroni's Multiple Comparison Test (Pam3CSK4; $\mathrm{n}=6$ ) or two-tailed paired Student's $t$ tests (convulxin and thrombin, each $\mathrm{n}=4$ ); $* * \mathrm{P}<0.01, * * * \mathrm{P}<0.001, \mathrm{~ns}=$ not significant.

Figure 4. Pam3CSK4- and convulxin-induced dense granule secretion and aggregation, but not that induced by thrombin, depends on intermediate TXA2-signalling

For aspirin (ASA)-treatment PRP was incubated with $100 \mu \mathrm{M}$ aspirin for 45 min at RT with gentle agitation. Aspirinated and non-aspirinated human platelets were subsequently isolated as described in "Material and Methods". Platelet ATP release (A) and aggregation (B) were determined in parallel as described in "Material and Methods". Isolated platelets were incubated with buffer or $5 \mu \mathrm{M}$ ICI 192,605 (ICI) for 5 min at $37^{\circ} \mathrm{C}$ with stirring at $900 \mathrm{rpm}$ prior to the addition of $7.5 \mu \mathrm{g} / \mathrm{ml}$ Pam3CSK4, $7.5 \mathrm{ng} / \mathrm{ml}$ convulxin, or $0.1 \mathrm{U} / \mathrm{ml}$ thrombin. All samples contain $0.05 \%$ DMSO as solvent control for the ICI-compound. The bar graphs show maximal ATP release (in $\mu \mathrm{M}$ ) and aggregation assessed after 10 min of stimulation (in $\%$ light transmission). Data of four individual experiments is presented as mean \pm S.E.M. and statistical analysis were performed by two-tailed paired Student's $t$ tests; $* * \mathrm{P}<0.01$, $* * * \mathrm{P}<0.001, \mathrm{~ns}=$ not significant.

Figure 5. Pam3CSK4- and convulxin-induced dense granule secretion, but not that provoked by thrombin, relies on integrin $\alpha_{\mathrm{II}} \beta_{3}$ outside-in signalling

Platelet ATP release (A) and aggregation (B) were determined in parallel as described in "Material and Methods". Isolated human platelets were incubated with buffer or $50 \mu \mathrm{g} / \mathrm{ml}$ abciximab for $5 \mathrm{~min}$ at $37^{\circ} \mathrm{C}$ with stirring at $900 \mathrm{rpm}$ prior to the addition of $7.5 \mu \mathrm{g} / \mathrm{ml}$ Pam3CSK4, 7.5 ng/ml convulxin, or $0.1 \mathrm{U} / \mathrm{ml}$ thrombin. The Pam3CSK4- and convulxinstimulated samples were after 10 min additively stimulated with $0.1 \mathrm{U} / \mathrm{ml}$ thrombin (indicated by the curved arrows). The bar graphs show maximal ATP release (in $\mu \mathrm{M}$ ) and aggregation 
assessed after $10 \mathrm{~min}$ of stimulation (in \% light transmission). Data of four individual experiments is presented as mean \pm S.E.M. and statistical analysis were performed by twotailed paired Student's $t$ tests; $* \mathrm{P}<0.05, * * \mathrm{P}<0.01, * * * \mathrm{P}<0.001$, ns $=$ not significant.

Figure 6. Pam3CSK4 evokes LAT and PLC $\gamma 2$ tyrosine phosphorylation as well as cytosolic $\mathrm{Ca}^{2+}$-mobilization in platelets from a Glanzmann's thrombasthenia patient

A: Isolated human platelets from a Glanzmann's thrombasthenia patient and an age- and gender-matching volunteer (control) were pre-warmed to $37^{\circ} \mathrm{C}$ with gentle rotating at 500 rpm and challanged with buffer, Pam3CSK4, or convulxin (CVX) at indicated concentrations for $10 \mathrm{sec}$ at $37^{\circ} \mathrm{C}$ with rotating at $900 \mathrm{rpm}$. Reactions were stopped by the addition of SDSsample buffer. Samples were analyzed by SDS-PAGE followed by Western blotting as described in "Material and Methods" using antibodies recognizing LAT phosphorylated at Tyr191 residues and unmodified $\beta$-tubulin or PLC $\gamma 2$ phosphorylated at Tyr759 residues and

unmodified PLC $\gamma 2$. The shown result is from one experiment. B: Isolated platelets were stimulated with $7.5 \mu \mathrm{g} / \mathrm{ml}$ Pam3CSK4 and maximal peak rises in cytosolic $\mathrm{Ca}^{2+}$ determined as described in "Material and Methods". The shown data is from one experiment performed in triplicate.

Figure 7. Pam3CSK4 and convulxin fail to induce platelet dense granule secretion from Glanzmann's thrombasthenia patient platelets

Platelet ATP release (A) and aggregation (B) were determined in parallel as described in "Material and Methods". Isolated human platelets from and an age- and gender-matching volunteer (control) were pre-warmed to $37^{\circ} \mathrm{C}$ for $5 \mathrm{~min}$ and stimulated with $7.5 \mu \mathrm{g} / \mathrm{ml}$ Pam3CSK4, $7.5 \mathrm{ng} / \mathrm{ml}$ convulxin, or $0.1 \mathrm{U} / \mathrm{ml}$ thrombin with stirring at $900 \mathrm{rpm}$. Likewise, platelets from a Glanzmann's thrombasthenia patient were pre-warmed to $37^{\circ} \mathrm{C}$ for $5 \mathrm{~min}$ and stimulated with $7.5 \mu \mathrm{g} / \mathrm{ml}$ Pam3CSK4 or $7.5 \mathrm{ng} / \mathrm{ml}$ convulxin with stirring at $900 \mathrm{rpm}$, followed by the addition of $0.1 \mathrm{U} / \mathrm{ml}$ thrombin after $3 \mathrm{~min}$ of stimulation (indicated by the curved arrows). The bar graphs show maximal ATP release (in $\mu \mathrm{M}$ ) and aggregation assessed after 10 min of stimulation (in \% light transmission). The shown data is from one experiment performed in triplicate.

\section{Figure 8. Pam3CSK4 does not cross-activate GPVI}

Platelet aggregation was determined as described in "Material and Methods". For (A) isolated human platelets were incubated with buffer or $1 \mathrm{ng} / \mathrm{ml}$ convulxin for $30 \mathrm{~min}$ at $37^{\circ} \mathrm{C}$ with 
gentle agitation prior to the addition of $7.5 \mathrm{ng} / \mathrm{ml}$ convulxin or $7.5 \mu \mathrm{g} / \mathrm{ml}$ Pam3CSK4 with stirring at $900 \mathrm{rpm}$. For (B) isolated human platelets were incubated with vehicle $(0.3 \%$ DMSO) or $300 \mu \mathrm{M} \mathrm{CCCP}$ for $90 \mathrm{~min}$ at $37^{\circ} \mathrm{C}$ with gentle agitation, and platelets were once more washed as described in "Material and Methods". Platelets then were stimulated with convulxin at indicated concentrations or with $7.5 \mu \mathrm{g} / \mathrm{ml}$ Pam3CSK4 while stirring at $900 \mathrm{rpm}$. Data of three individual experiments is presented as mean \pm S.E.M. and statistical analysis were performed by two-tailed paired Student's $t$ tests; $* * \mathrm{P}<0.01$, ns $=$ not significant. 
Fälker K., et al. Figure 1
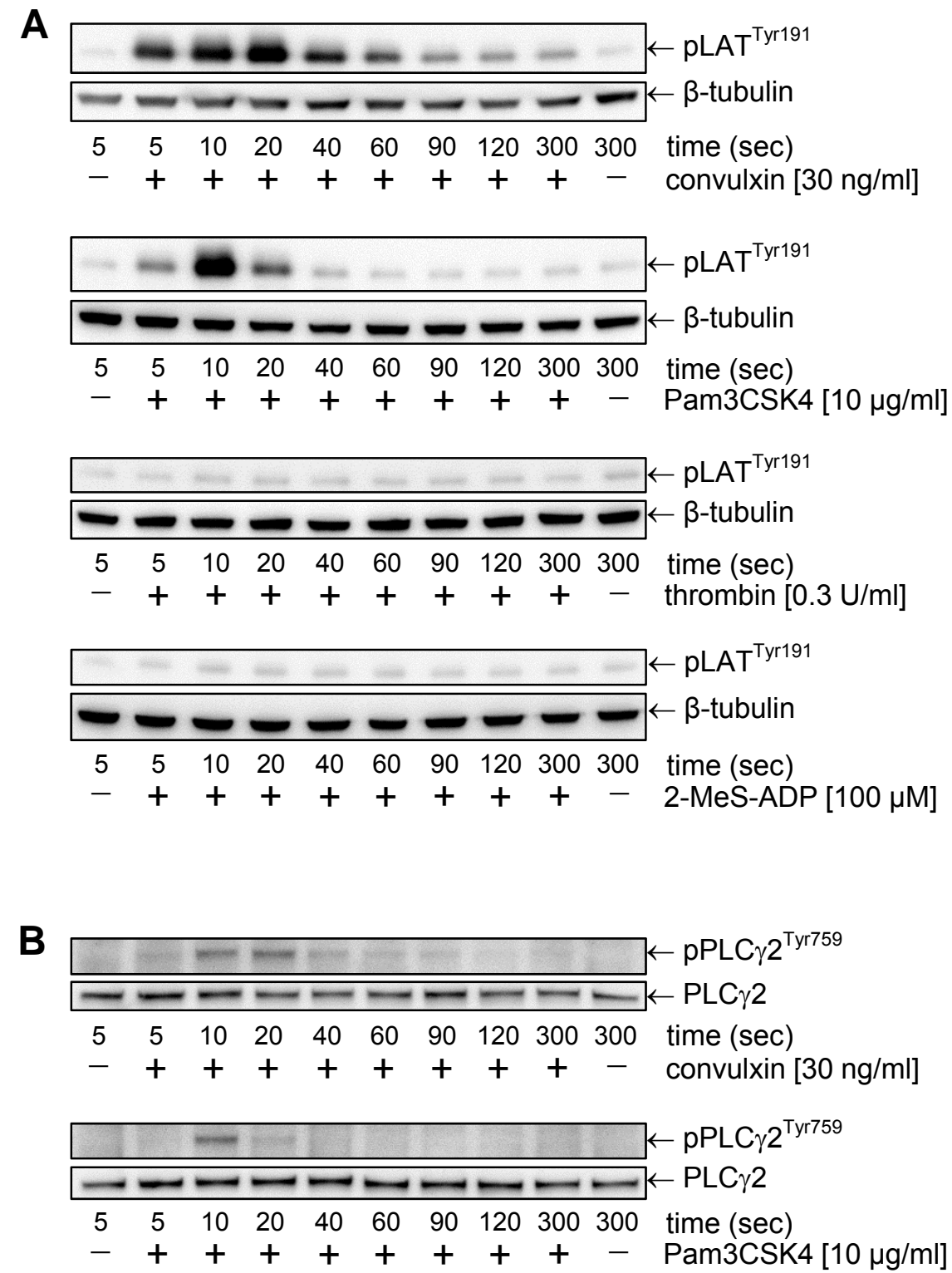
Fälker K., et al. Figure 2

A

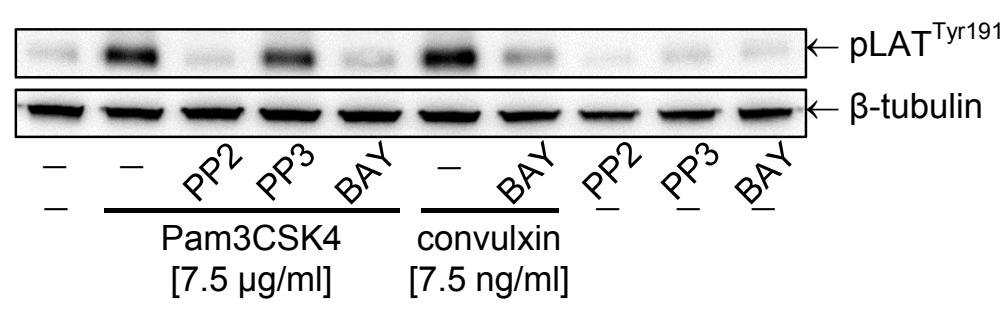

B

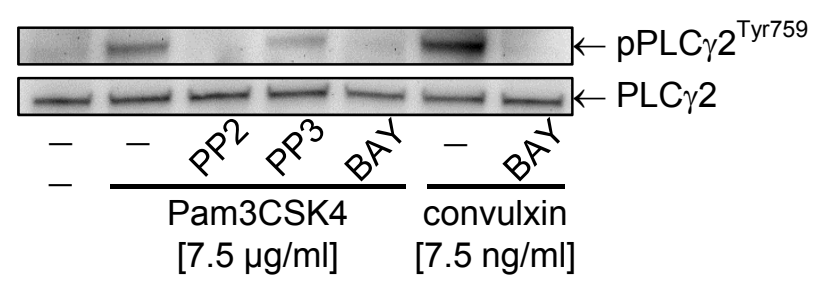

C

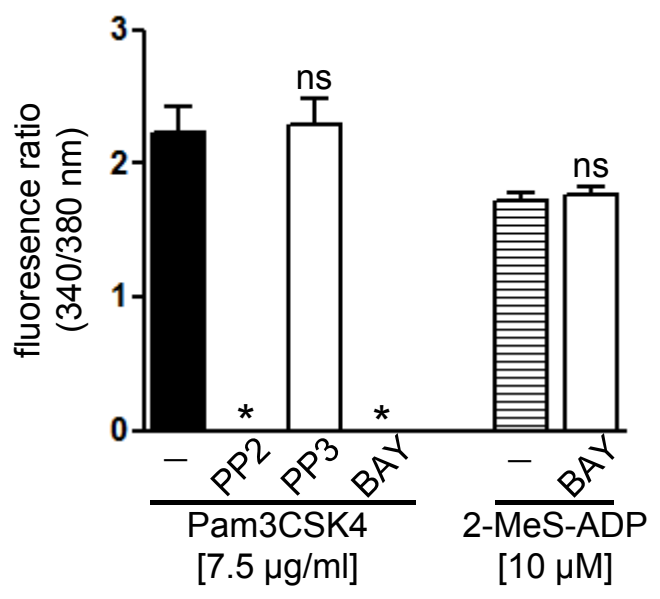


Fälker K., et al. Figure 3
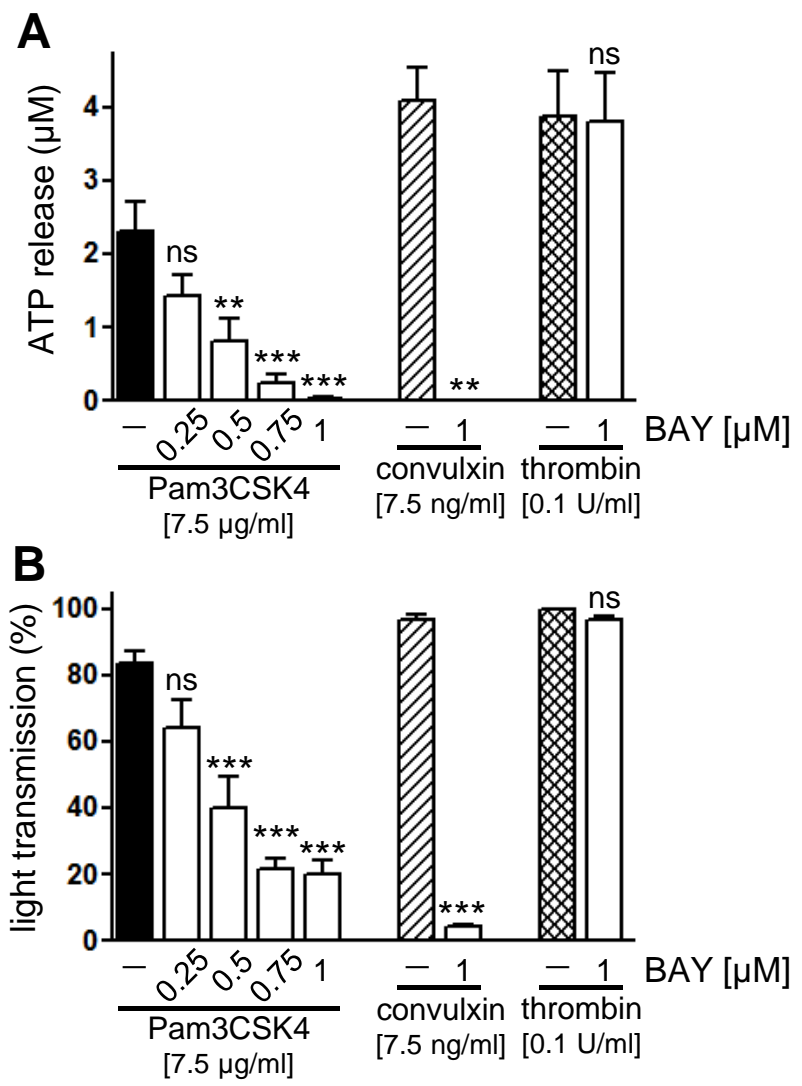
Fälker K., et al. Figure 4

A

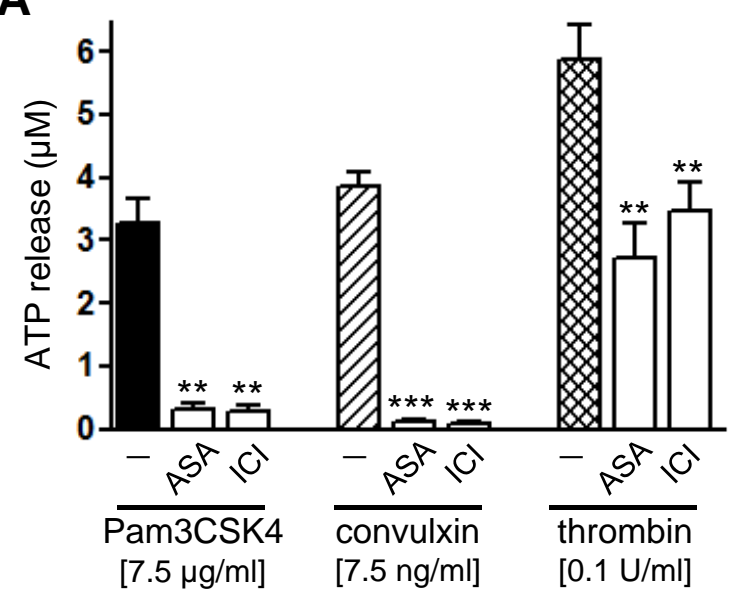

B

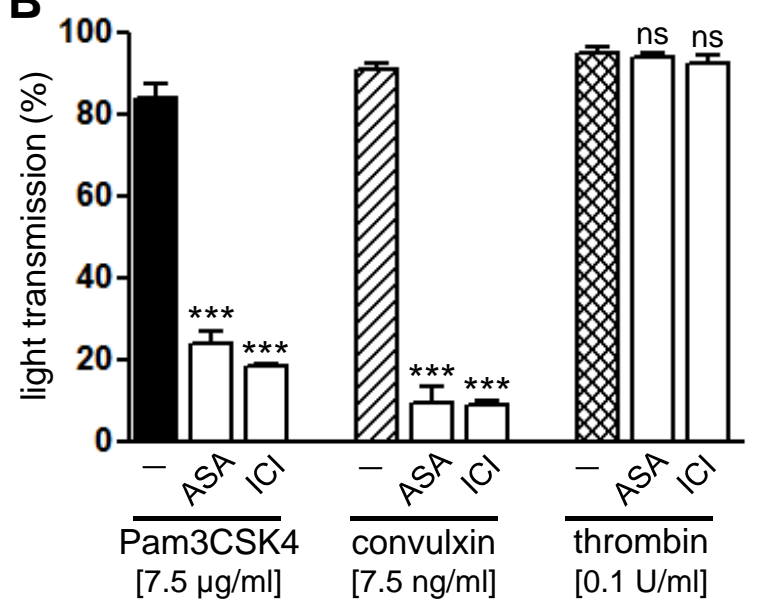


Fälker K., et al. Figure 5

A
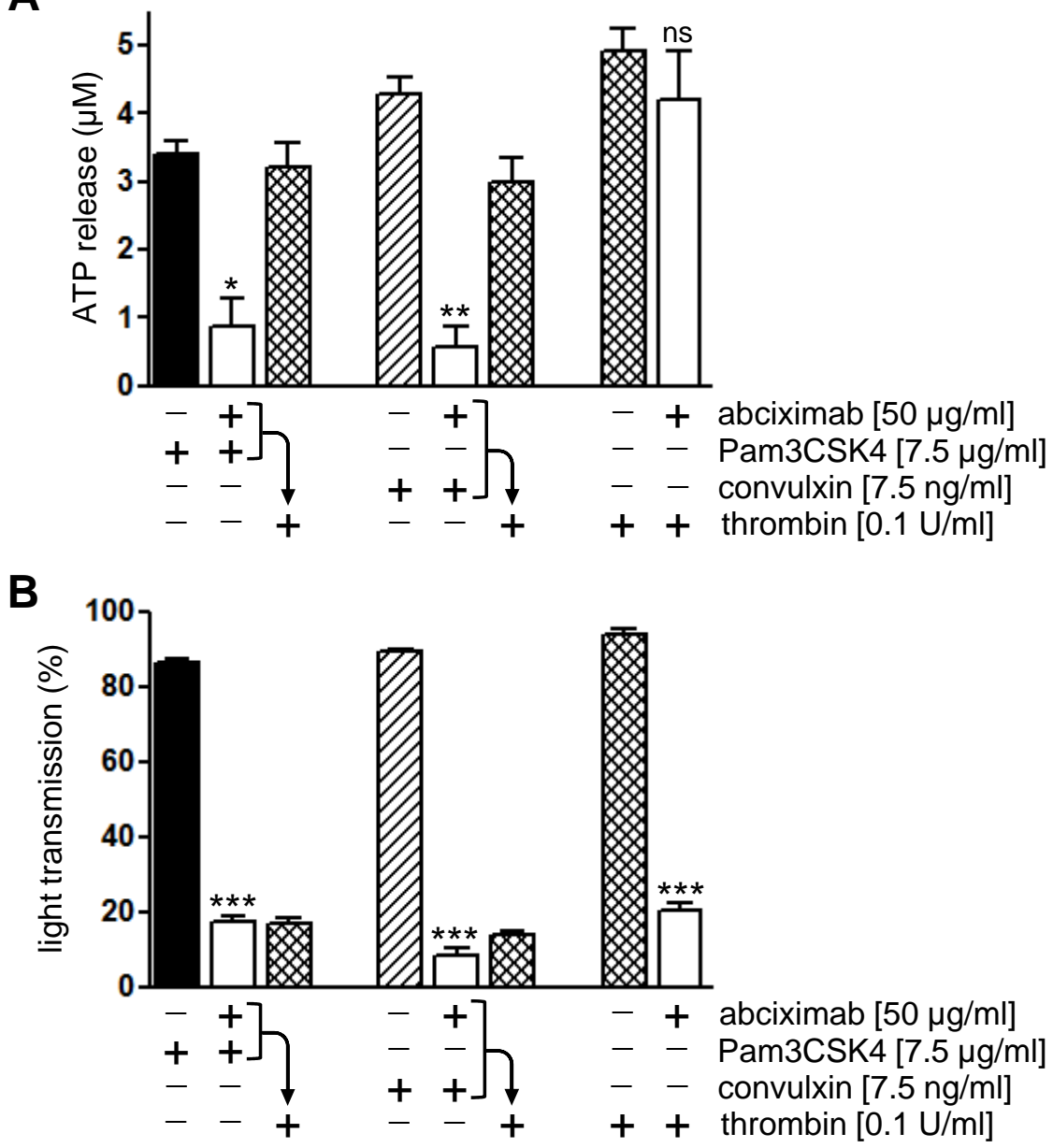
Fälker K., et al. Figure 6

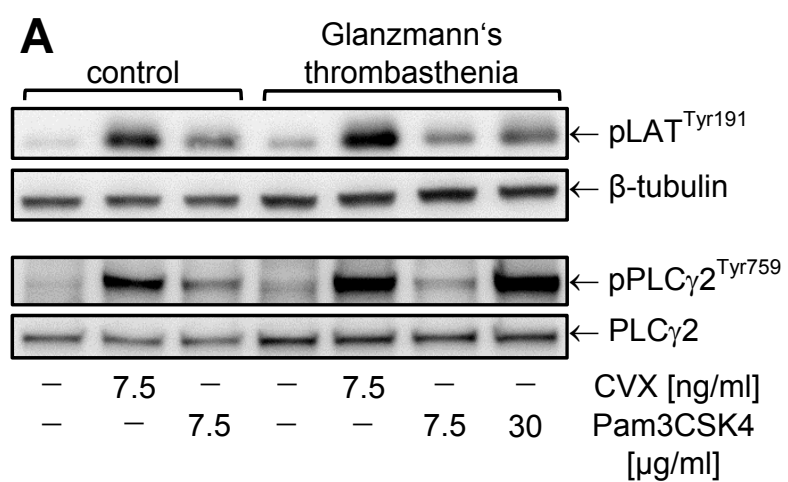

B

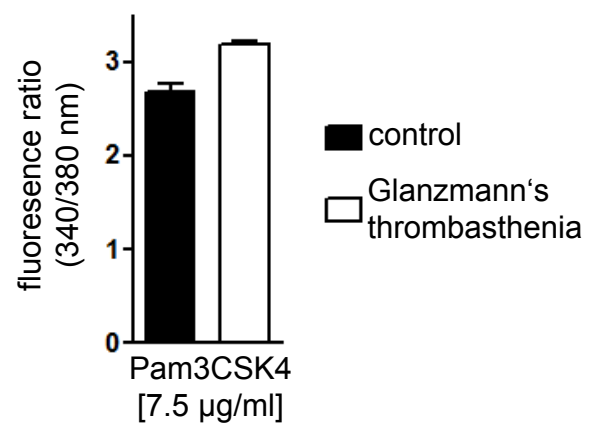


Fälker K., et al. Figure 7
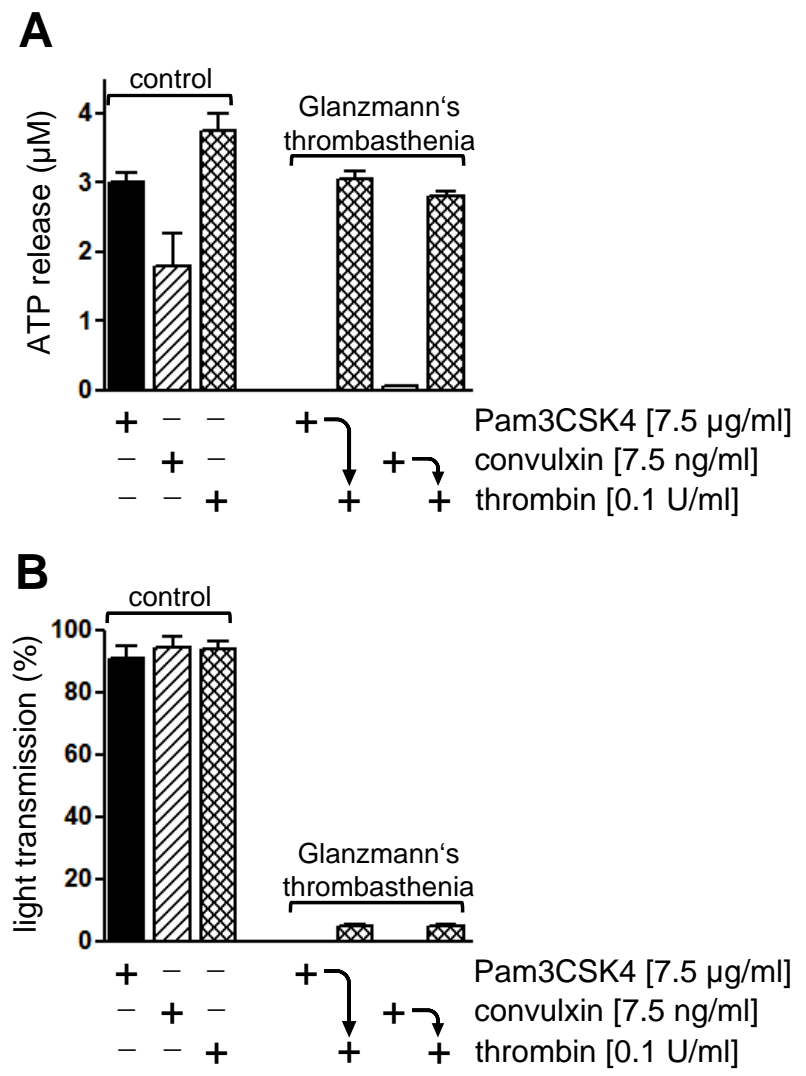
Fälker K., et al. Figure 8
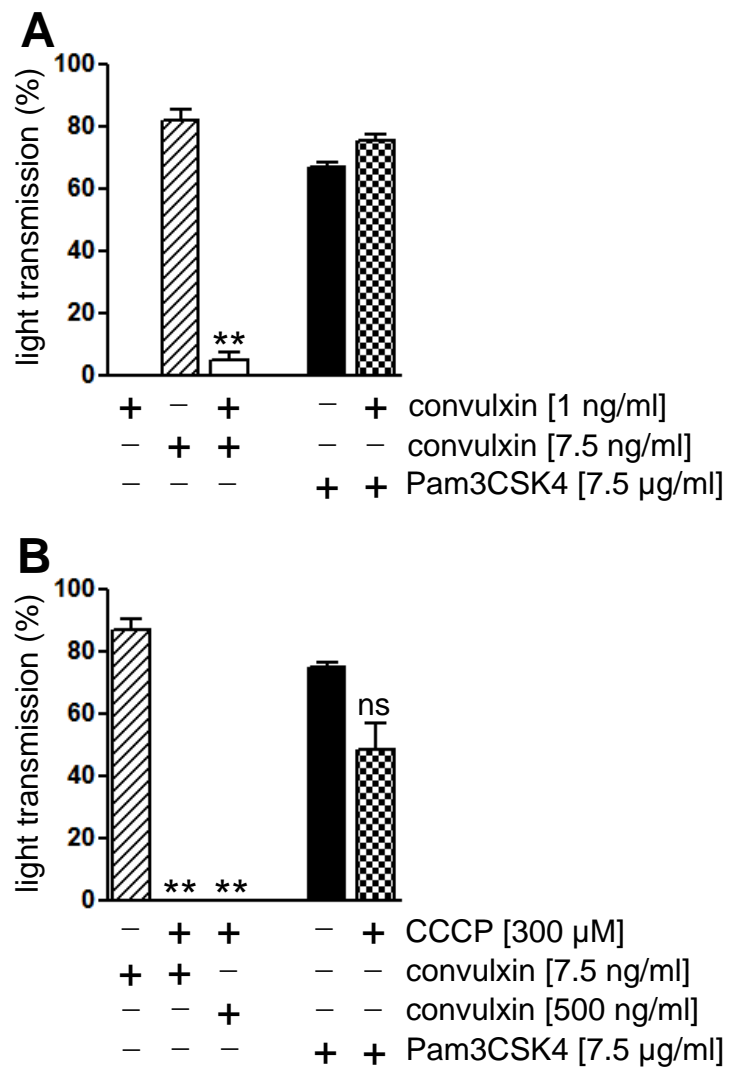